\title{
Swimming and bipedal bottom-running in the pig-nosed turtle Carettochelys insculpta Ramsay, 1886
}

\author{
John Davenporta ${ }^{\mathrm{a}}$, Julia Davenport ${ }^{\mathrm{a}}$, Cheong-Hoong Diong ${ }^{\mathrm{b}}$ and K.H. Low \\ aSchool of Biological, Earth and Environmental Sciences, University College Cork, Cork, Ireland; 'bivision of \\ Natural Sciences and Science Education, Nanyang Technological University, Singapore; 'School of \\ Mechanical and Aerospace Engineering, Division of Mechatronics and Design, Nanyang Technological \\ University, Singapore
}

\begin{abstract}
The pig-nosed freshwater turtle Carettochelys insculpta Ramsay, 1886 has paddle-shaped foreflippers that resemble those of sea turtles. These turtles exhibit a wide range of swimming capabilities. As well as swimming by the action of synchronized foreflippers alone, they sometimes used alternate hindlimb action at the same time. They could swim by ipsilaterally synchronized action of all four limbs, or by hindlimb action alone (combined with stabilizer/lift function of the foreflippers). The turtles also showed flexibility in bottom-walking. Besides the ipsilaterally synchronized quadrupedal action characteristic of other freshwater turtles, they exhibited a bipedal walking mechanism never previously described. Propelled by alternate action of the hindlimbs, the animals held the head and plastron above the substratum, with the large foreflippers acting to provide anterior lift and stability against roll and yaw. Because both hindlimbs were sometimes off the substratum simultaneously during bipedal locomotion, their duty factors were $<0.5$, implying a bipedal run.
\end{abstract}

\section{ARTICLE HISTORY}

Received 16 December 2015

Accepted 21 March 2016

\section{KEYWORDS}

Carettochelys; large foreflippers; pig-nosed turtles; bipedal running

\section{Introduction}

The pig-nosed turtle Carettochelys insculpta (Ramsay 1886) is a large river turtle $(<0.7 \mathrm{~m}$ shell length, $<20 \mathrm{~kg}$ body mass), with a limited geographical riverine distribution [Southern Papua New Guinea and Irian Jaya (Indonesia) and Northern Territory (Australia)]. It was classified as Vulnerable by the IUCN in 2000 (IUCN Redlist 2015) in the light of its use in the pet trade, capture for food, and because of regional habitat degradation. The species is the sole survivor of a cryptodiran family (Carettochelyidae), once global in distribution and of great antiquity (40 million years). The closest living relatives are softshell turtles (Trionychidae: see Bever 2004 for review). Carettochelys insculpta is an omnivore that eats leaves, fruits (e.g. of mangroves), crustaceans, insects and molluscs (Wilson and Swan 2003; Georges, Doody et al. 2008). Although predominantly freshwater, the adults occur in estuaries (Groombridge 1982; Eisemberg, Rose,

CONTACT John Davenport j.davenport@ucc.ie E School of Biological, Earth and Environmental Sciences, University College Cork, Distillery Fields, North Mall, Cork, Ireland 
Yaru, Amepou et al. 2015) and even exploit coastal bays and sometimes nest on sea beaches (Georges, Alacs et al. 2008).

Since the species' discovery, many observers (e.g. Pritchard 1979) have highlighted the fact that $C$. insculpta has large, paddle-shaped, two-clawed foreflippers that have a great external resemblance to those of sea turtles. Legler (1993) remarked that pignosed turtles use the foreflippers in unison to achieve 'a "flying" motion for forward propulsion', though he also noted that 'when chased, however, C. insculpta swims rapidly by moving the flippers alternately and coordinating them with the hind feet in a trot-type swimming gait'. Carettochelys insculpta is also unique among living nonmarine uatic turtles in that the forelimbs are larger than the hindlimbs. Rivera et al. (2013) recently conducted a kinematic analysis of swimming in C. insculpta; they concluded that the synchronized forelimb action was more akin to the 'rowing' action of such freshwater turtles as Trachemys scripta (Thunberg in Schoepff 1792) than it was to the flapping locomotion of the marine turtle Caretta caretta (Linnaeus 1758).

Singapore Zoo has a number of $C$. insculpta held in outdoor display pools. Our study arose from an opportunity to study a small number of quarantined turtles for a short period before they were released into those pools. We were able to make qualitative observations on their swimming and quantitative measurements of swimming and bottom-walking speeds. However, unexpected information was also collected that revealed a novel form of bipedal bottom-walking in this monotypic species.

\section{Material and methods}

Three specimens of disparate size (small, medium, large) of C. insculpta were made available (under stringent conditions) by the Singapore Zoo. They probably came from Papua New Guinea, but this is not certain; they were confiscated animals from illegal trading. Their dimensions are given in Table 1. The smallest gravid female that has been documented in the wild was $38 \mathrm{~cm}$ in Australia and $41 \mathrm{~cm}$ in Papua New Guinea (Georges, Doody et al. 2008). The smallest size recorded in coastal areas was $43 \mathrm{~cm}$ (Eisemberg, Rose, Yaru, Georges 2015), so all three specimens were young animals. All three were being held in quarantine, and were about to be transferred to display facilities. They were transferred to the School of Mechanical and Aerospace Engineering, Nanyang Technological University on the understanding that they would be held there for no more than 30 hours (in relatively small holding vessels, with small amounts of vegetable food) and manipulated as little as possible. Some extra qualitative observations were made on display turtles, but filming of them was not possible.

Table 1. Dimensions (mm) of studied specimens of Carettochelys insculpta.

\begin{tabular}{lccc}
\hline & \multicolumn{3}{c}{ Specimen } \\
\cline { 2 - 4 } Dimension & 1. Small & 2. Medium & 3. Large \\
\hline Straight carapace length & 128 & 199 & 349 \\
Curved carapace length & 135 & 210 & 397 \\
Plastron length & 110 & 165 & 305 \\
Maximum shell width & 118 & 175 & 274 \\
Snout-tail length & 197 & 351 & 514 \\
\hline
\end{tabular}

Estimated from video still images using straight carapace length as scale. 
All experiments were conducted in a room regulated at $26-27^{\circ} \mathrm{C}$; this is the optimum holding temperature recommended by Dorrian (1994). The turtles' separate holding vessels were also held in the room. Turtles were filmed while moving in an aluminium-framed glass tank $59 \mathrm{~cm}$ deep, $116 \mathrm{~cm}$ wide and $298 \mathrm{~cm}$ long. Most filming was done from a position normal to the long axis of the tank and $300 \mathrm{~cm}$ away from the side of the tank, although filming of bottom-walking in the small turtle was accomplished from above. A Canon Digital 8 videocamera operating at $30 \mathrm{~Hz}$ (with a $0.001 \mathrm{~s}$ shutter speed) was used. Most swimming data were collected from the large and medium-sized animals; the small turtle was unwilling to swim. Full kinematic analysis was not possible, mainly because of the size disparities, but also because the turtles rarely sustained a particular swimming gait for more than two cycles, and then not in a straight line. Movement analysis was accomplished by loading film onto the MotionAnalysisTools software package (Ottawa Hospital Rehabilitation Centre, Ottawa, Canada). Scale was provided by reference to the turtles' shell dimensions (Table 1).

\section{Results}

\section{Swimming}

Pig-nosed turtles can swim with simultaneous foreflipper action, but that propulsion is achieved by a paddle/scoop action, not by a wing-like mechanism. The axis of flipper beat is horizontal rather than vertical. The large and medium-sized specimens both used synchronized foreflipper swimming when swimming steadily in the middle of the water column of the study tank. However, the involvement of hindlimbs varied. When swimming horizontally, both specimens often showed alternate hindlimb action. When the medium-sized animal swam downwards the hindlimbs were not used. Both the medium-sized and large turtles often showed hindlimb action only, but with the foreflippers held motionless in an elevated position. All three pig-nosed turtles also showed much of the ipsilaterally synchronized alternate limb action that is characteristic of all freshwater aquatic turtles whether swimming or walking. In the case of the small specimen, this was the only swimming gait observed. The turtles all showed great manoeuvrability at slow speed, with sweeps of a single foreflipper at a time allowing very tight turns. Within the Singapore Zoo display facilities, other pignosed turtles were seen to swim slowly using simultaneous foreflipper action, particularly when swimming in open water. However, they tended to use the trot-type swimming gait when moving around the roots of vegetation, or among rocks. A hatchling seen in a commercially published film (BBC 2008) used a dog-paddle action (in open water) and did not use its foreflippers simultaneously. Swimming speeds recorded for the medium-sized and large pig-nosed turtles when swimming with synchronized foreflippers are shown in Table 2.

\section{Bottom-walking/running}

The small and medium-sized turtles both showed bottom-walking of the type described previously for many freshwater turtles (i.e. diagonally synchronized alternate limb action). No illustrations are presented here, though bottom-walking speeds are 
Table 2. Speed of locomotion in single small, medium and large specimens of Carettochelys insculpta.

\begin{tabular}{|c|c|c|c|c|}
\hline Mode of locomotion & $\begin{array}{l}\text { Mean speed } \\
\left(m \mathrm{~s}^{-1}\right)\end{array}$ & $\begin{array}{l}\text { Speed range } \\
\left(\mathrm{m} \mathrm{s}^{-1}\right)\end{array}$ & $\begin{array}{c}\text { Mean speed } \\
\text { (body lengths } s^{-1} \text { ) }\end{array}$ & $\begin{array}{c}\text { Speed range } \\
\text { (body lengths } s^{-1} \text { ) }\end{array}$ \\
\hline \multicolumn{5}{|l|}{$\begin{array}{l}\text { A. Synchronized foreflipper } \\
\text { swimming }\end{array}$} \\
\hline 1. Medium $(n=3)$ & 0.21 & $0.17-0.23$ & 0.59 & $0.49-0.65$ \\
\hline 2. Large $(n=5)$ & 0.22 & $0.14-0.27$ & 0.42 & $0.28-0.52$ \\
\hline \multicolumn{5}{|l|}{ B. Bottom-walking } \\
\hline 1. Small $(n=3)$ & 0.11 & $0.11-0.20$ & 0.58 & $0.56-0.61$ \\
\hline 2. Medium $(n=1)$ & 0.05 & - & 0.14 & - \\
\hline \multicolumn{5}{|l|}{ C. Bipedal bottom running } \\
\hline 1. Large $(n=3)$ & 0.19 & $0.16-0.24$ & 0.36 & $0.31-0.46$ \\
\hline
\end{tabular}

$n=$ number of movement sequences analysed.

Small and medium specimens also showed bipedal bottom locomotion, but never when moving perpendicular to camera.

presented in Table 2. During this type of locomotion the plastron was close to or in contact with the substratum.

The medium-sized and large turtles both showed a form of chelonian bottom-walking never previously described; this is illustrated for the large turtle in Figures 1-3 (the medium-sized specimen only showed this form of bottom-walking when moving away from the camera). The turtles moved above the substratum, with only the hindlimbs contacting the substratum itself; the foreflippers being held in the elevated position of Figure $3(A)$, though with occasional downwards and backwards flicks of the tips of the flippers (Figure 1, fields 4 and 5). The snout was directed downwards, with the nostrils close to the substratum; the eyes were directed forwards. Close examination of the sequences showed that this bipedal bottom-walking was accompanied by slight lateral
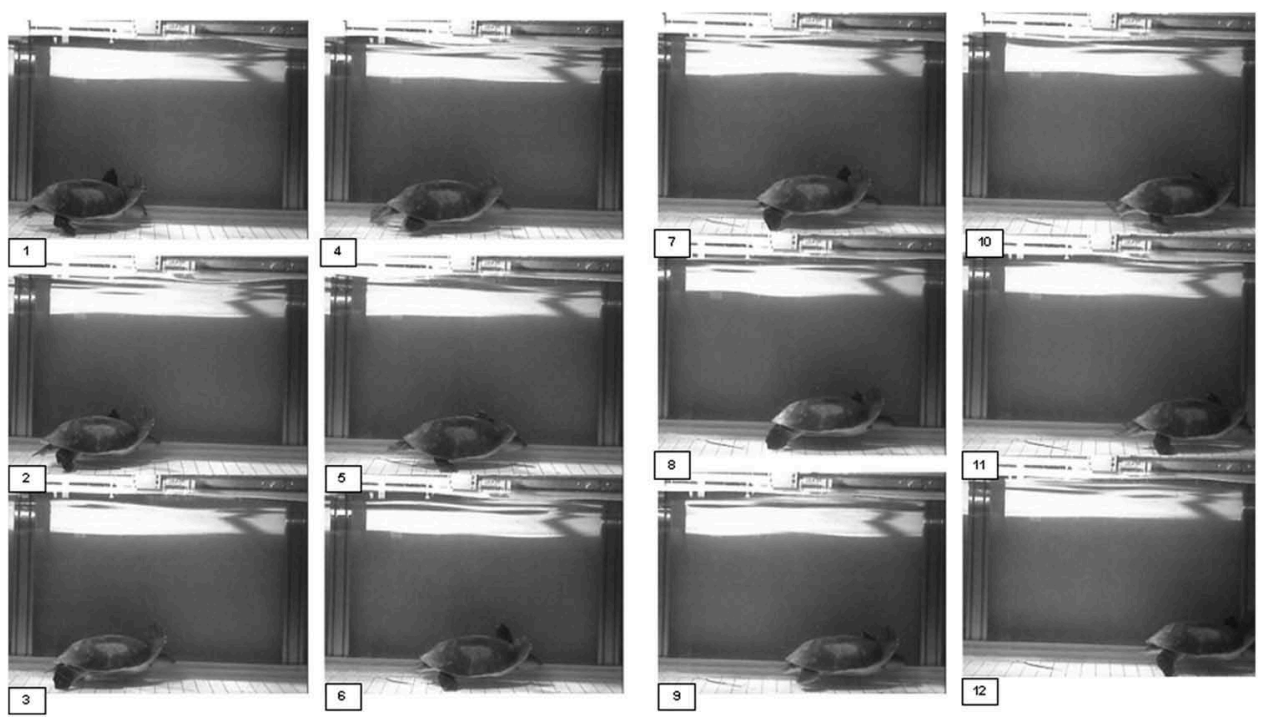

Figure 1. Large Carettochelys insculpta bipedal bottom-running. Intervals of 10 fields ( $0.33 \mathrm{~s})$ between numbered fields. Note that, at fields 4 and 5, the two foreflipper tips are both flipped downwards and posteriorly. 
1.

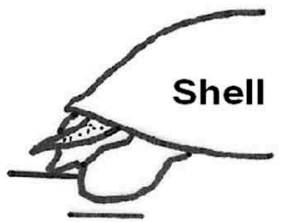

2.

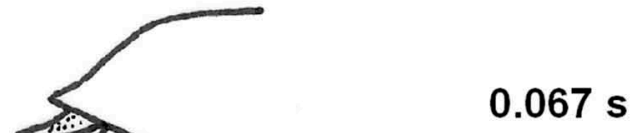

3.

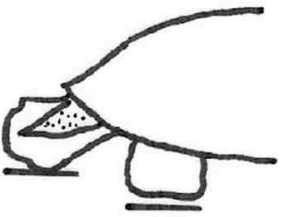

4.

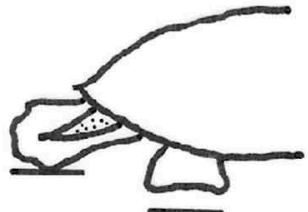

5.

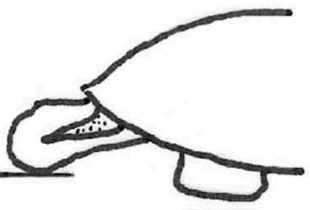

6.

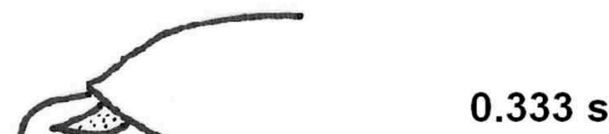

7.

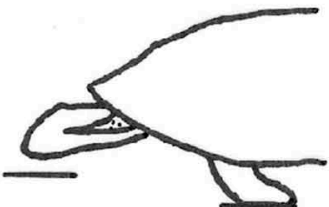

$0.133 \mathrm{~s}$

$0.200 \mathrm{~s}$

$0.267 \mathrm{~s}$

$0.400 \mathrm{~s}$

$0.467 \mathrm{~s}$

Figure 2. Detail of hindlimb action during bipedal bottom running in large Carettochelys insculpta. Numerals indicate field sequence. Tail is stippled. Short horizontal lines indicate substratum beneath hindlimbs. Note that, at field 6, neither rear limb is in contact with the substratum. 

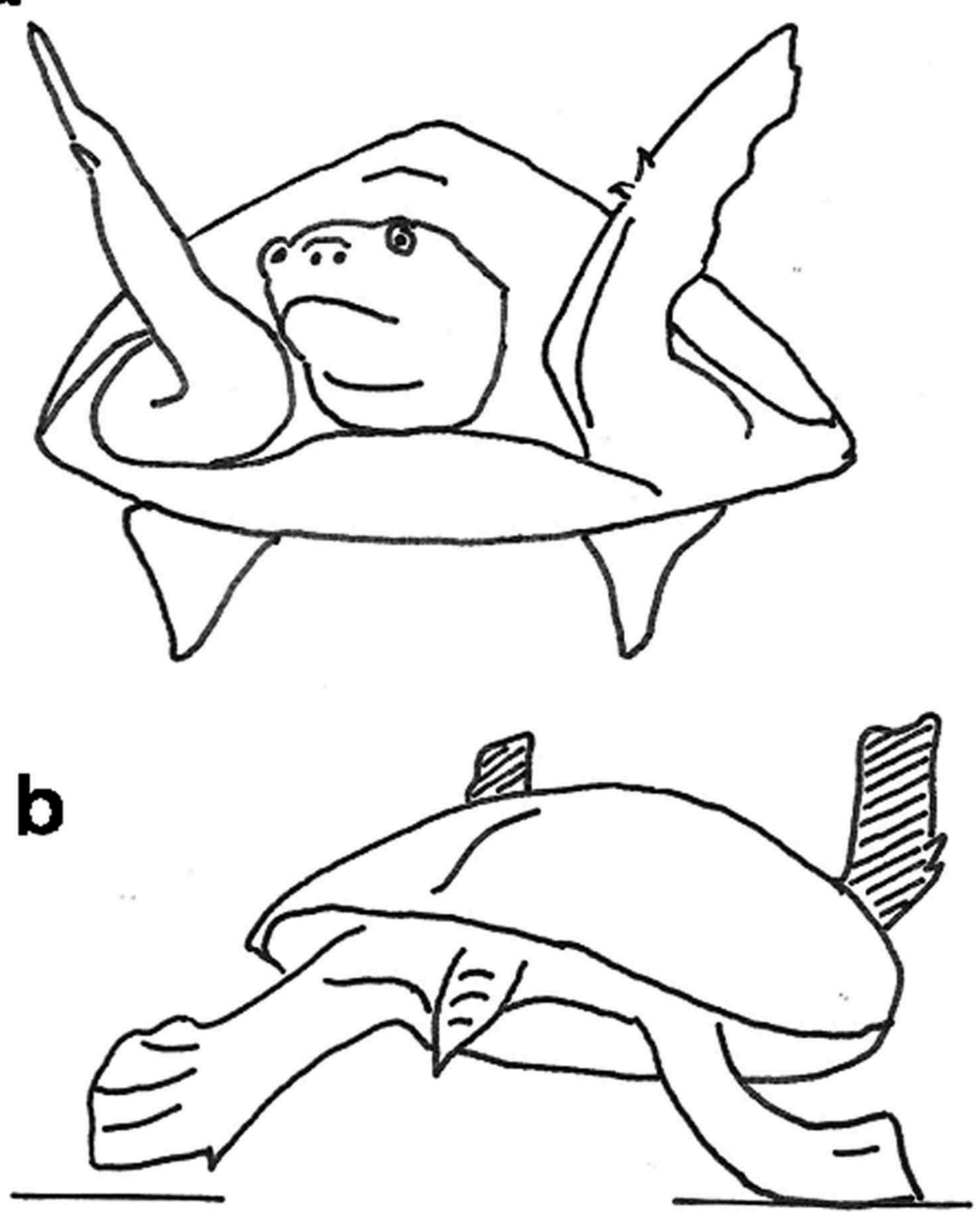

Figure 3. Images of large Carettochelys insculpta. (A) Turtle gliding towards camera. (B) Moving bipedally on substratum away from camera; forelimbs are stippled. Short horizontal lines indicate substratum beneath hindlimbs.

rocking of the shell, the shell rising on the supported side and falling on the side with the hindlimb off the substratum. Full gait analysis could not be conducted from the film collected in this study. However, from Figure 2 it can be seen that there were occasions (see field 6) when both hindlimbs lost contact with the substratum; because their duty factors will consequently be $<0.5$, this means that this bipedal bottom locomotion is technically a run rather than a walk (see Alexander 2004 for review). Bottom-walking 
speeds are presented in Table 2. Bottom-walking was fast in the small specimen (comparable with swimming speeds in the other two turtles, at least in terms of body lengths $\mathrm{s}^{-1}$ ), but slow in the medium-sized turtle, which moved at about $23 \%$ of its synchronized swimming speed. In contrast, the large turtle's bipedal bottom-running was at $86 \%$ (mean $0.19 \mathrm{~m} \mathrm{~s}^{-1}$ ) of its mean synchronized foreflipper swimming speed (mean $0.22 \mathrm{~m} \mathrm{~s}^{-1}$ ).

\section{Discussion}

\section{Swimming}

Our qualitative observations of swimming using synchronized foreflipper action are compatible with the observations of Rivera et al. (2013); C. insculpta is an underwater 'flapper', not a 'flier'. This study also reveals that, despite its enlarged foreflippers, the pig-nosed turtle is a relatively slow swimmer at least as far as the young study animals were concerned. Maximum observed speeds for the medium-sized and large turtles when swimming using synchronized foreflippers were 0.65 and 0.52 body lengths $\mathrm{s}^{-1}$ respectively (Table 2). Meaningful comparisons with other species are difficult as relatively few measurements have been made, and those were under non-standard conditions. For example, Davenport et al. (1997) found that juvenile (10.5-12.2 cm snout-tail length) marine green turtles [Chelonia mydas (Linnaeus 1758)] could sustain mean speeds of 3.31 body lengths $\mathrm{s}^{-1}$ when swimming against a current and used ipsilaterally synchronized dog-paddling at speeds below $0.8-1.4$ body lengths $\mathrm{s}^{-1}$. Even freshwater turtles such as Trachemys scripta and Mauremys caspica (Gmelin 1774) can reach speeds of 1-2 body lengths $s^{-1}$ using dog-paddling (Davenport et al. 1984), though probably only for short periods. It may be that pig-nosed turtles are capable of long duration slow swimming, as they are omnivores that forage widely in large river systems; more field data are needed to confirm/deny this.

\section{Bottom-walking/running}

'Normal' quadrupedal bottom-walking by the small and medium-sized pig-nosed turtles was unremarkable. In contrast, the bipedal walking/running shown by the medium-sized and large turtles has never previously been reported in any turtle species. Bipedalism has been extensively studied (see Alexander 2004 for review) in terrestrial animals (e.g. birds, lizards, cockroaches, humans), but has not been reported in aquatic animals save in very slow-moving frogfish (Pietsch and Grobecker 1987) and in a single octopus species (Huffard et al. 2005). The remarkable bottom-running of the large specimen of C. insculpta was nearly as fast as its synchronized foreflipper swimming. The bipedal action of the hindlimbs takes place far behind the centre of mass of the animal and it seems certain that the forward-pitching imposed by their reaction against the substratum is opposed by lift generated by the large forelimbs held in the posture seen in Figures 1 and $3(\mathrm{~A})$. Essentially the animal glides smoothly over the substratum, being kicked along by the hindlimbs. The functional significance of this ability may lie in an ability to approach benthic prey stealthily, with the disturbance of force generation occurring far posterior to the eyes and jaws, but confirmation of this would require field 
investigation. Obviously this form of bipedalism is wholly dependent on the pig-nosed turtles operating in a supportive medium so that immersed weight is low and hence foreflipper lift can hold the forepart of the body above the substratum.

\section{Evolutionary and ecological significance}

Because of the constraints of the study (imposed by small sample size and disparate specimen size), there are many questions still to be answered about the locomotion of C. insculpta. For example, it would seem likely that there may be ontogenetic differences in locomotory capacity, with small pig-nosed turtles having a narrower repertoire than older animals. However, the results presented here demonstrate that $C$. insculpta employs synchronized foreflipper action for different purposes from extant marine turtles. The enlarged foreflippers appear to function primarily to deliver longitudinal and lateral stability plus quiet swimming and bottom-walking rather than enhanced speed and efficiency. It is noteworthy that the axis of flipper beat is horizontal, but higher than the head and much of the shell, therefore further away from the substratum than in other turtle species. Possibly, in the evolution of marine turtle locomotion, enlargement and synchronization of the foreflippers preceded the development of liftbased submarine flying.

\section{Acknowledgements}

This study was wholly reliant on the generosity of the Singapore Zoo in permitting study of specimens of $C$. insculpta. We are particularly grateful to Charlene Yeong, the Zoo's Research and Conservation Officer for her good offices in arranging for the turtles' loan and their transfer to and from Nanyang Technological University. Chong Chee Wee and Hu Tianjiang are thanked for valuable technical assistance. JD is grateful to Prof. Peter KL Ng (Department of Biological Sciences, National University of Singapore) who helped to organize his visit to Singapore; he is also grateful to University College Cork for awarding him sabbatical leave.

\section{Disclosure statement}

No potential conflict of interest was reported by the authors.

\section{References}

Alexander R. 2004. Bipedal animals and their differences from humans. J Anat. 204:321-330.

BBC. 2008. Life in Cold Blood. London: BBC Worldwide.

Bever GS 2004. Carettochelys insculpta. (On-line), Digital Morphology. [cited 2015 Dec 10]. Available from: http://digimorph.org/specimens/Carettochelys_insculpta/.

Davenport J, De Verteuil N, Magill SH. 1997. The effects of current velocity and temperature upon swimming in juvenile green turtles Chelonia mydas L. Herpetol J. 7:143-147.

Davenport J, Munks S, Oxford PJ. 1984. A comparison of the swimming of marine and freshwater turtles. Proc Roy Soc Lond. 220:447-475.

Dorrian C. 1994. Captive management of Carettochelys insculpta. Herpetofauna. 24:15-18.

Eisemberg CC, Rose M, Yaru B, Amepou Y, Georges A. 2015. Salinity of the coastal nesting environment and its association with body size in the estuarine pig-nosed turtle. J Zool. 295:65-74. 
Eisemberg CC, Rose M, Yaru B, Georges A. 2015. Spatial and temporal patterns of harvesting of the vulnerable pig-nosed turtle Carettochelys insculpta in the Kikori region, Papua New Guinea. Oryx. 49:659-668.

Georges A, Alacs E, Pauza M, Kinginapi F, Ona A, Eisemberg C. 2008. Freshwater turtles of the Kikori Drainage, Papua New Guinea, with special reference to the pig-nosed turtle, Carettochelys insculpta. Wildl Res. 35:700-711.

Georges A, Doody JS, Eisemberg C, Alacs EA, Rose M. 2008. Carettochelys insculpta Ramsay 1886pig-nosed turtle, Fly River turtle. Chelonian Res Monogr. 5:009-0017. Available from: http:// www.iucn-tftsg.org/wp-content/uploads/file/Accounts/crm_5_009_insculpta_v1_2008.pdf

Gmelin SG. 1774. Reise durch Russland zur Untersuchung der drey Natur-Reiche. St. Pétersbourg: Kayserliche Academie der Wissenschaften.

Groombridge B. 1982. IUCN Amphibia-Reptilia Red Data Book. Part 1 Testudines Crocodylia Rhynchocephalia. Gland: IUCN.

Huffard CL, Boneka F, Full RJ. 2005. Underwater bipedal locomotion by octopuses in disguise. Science. 307:1927.

IUCN Redlist 2015. Available from: http://www.iucnredlist.org/details/3898

Legler JM. 1993. Morphology and Physiology of the Chelonia. Ch. 16. In: Glasby CG, Ross GJB, Beesley PL, editors. Fauna of Australia (Vol. 2A). Canberra: Australian Government Publishing Service; p. 23.

Linnaeus C. 1758. Systema Naturae ed. p.10. Holmiae: Laurentii Salvii.

Pietsch TW, Grobecker DB. 1987. Frogfish of the world. Systematics, zoogeography and behavioural ecology. Stanford (CA): Standford University Press.

Pritchard PCH. 1979. Encyclopedia of Turtles. Neptune (NJ): TFH.

Ramsay EP. 1886. On a new genus and species of fresh water tortoise from the Fly River, New Guinea Proc. Linn Soc New South Wales. 1:158-162.

Rivera AR, Rivera G, Blob RW. 2013. Forelimb kinematics during swimming in the pig-nosed turtle, Carettochelys insculpta, compared with other turtle taxa: rowing versus flapping, convergence versus intermediacy. J Exp Biol. 216:668-680.

Schoepff JD. 1792. Historia Testudinum Iconibus Illustrata. [part 1]. Erlangae: JJ Palm.

Wilson S, Swan G. 2003. A complete guide to the reptiles of Australia. Sydney: New Holland Publishers Pty. 